\title{
Restrição do 16S-23S DNAr intergênico para avaliação da diversidade de Azospirillum amazonense isolado de Brachiaria spp.
}

\author{
Fábio Bueno dos Reis Junior(1), Verônica Massena Reis(2) e Kátia Regina dos Santos Teixeira(2)
}

(1)Embrapa Cerrados, BR 020, Km 18, CEP 73301-970 Planaltina, DF. E-mail: fabio@cpac.embrapa.br (2)Embrapa Agrobiologia, BR 465, Km 7, CEP 23851-970 Seropédica, RJ. E-mail: veronica@cnpab.embrapa.br, katia@cnpab.embrapa.br

\begin{abstract}
Resumo - O objetivo deste trabalho foi avaliar a diversidade intra-específica de isolados de Azospirillum amazonense e estabelecer a possível influência de diferentes espécies de Brachiaria ssp. e diferentes condições edafoclimáticas. A caracterização da diversidade desses isolados foi conduzida, utilizando-se a análise de restrição da região intergênica 16S-23S DNAr. As estirpes estudadas separaram-se em dois grupos, definidos a $56 \%$ de similaridade. As espécies de Brachiaria ssp. influenciaram a diversidade de estirpes. A maioria dos isolados oriundos de $B$. decumbens e $B$. brizantha está inserida no primeiro grupo, enquanto os oriundos de B. humidicola concentram-se no segundo grupo.
\end{abstract}

Termos para indexação: fixação biológica de nitrogênio, bactérias diazotróficas, ecologia microbiana, pastagens.

\section{Restriction of 16S-23S intergenic rDNA for diversity evaluation of Azospirillum amazonense isolated from different Brachiaria spp.}

\begin{abstract}
The aim of this work was to study the intra-specific diversity of Azospirillum amazonense isolates and to establish possible influences of different Brachiaria spp. and edaphoclimatic conditions. The characterization of the diversity among the isolates of $A$. amazonense studied was conducted using restriction analysis of the 16S-23S rDNA intergenic spacer region. The evaluated strains were separated in two groups, defined at 56\% of similarity. Brachiaria spp. showed effects on strain diversity. Most part of the isolates from $B$. decumbens and B. brizantha are inserted in the first group, while B. humidicola isolates concentrate in the second group.
\end{abstract}

Index terms: biological nitrogen fixation, diazotrophic bacteria, microbial ecology, pastures.

\section{Introdução}

A limitação de N é um dos mais importantes fatores que levam à degradação das pastagens. Entretanto, existe a possibilidade de que parte desse nutriente possa ser disponibilizada pela fixação biológica do nitrogênio atmosférico (FBN) que, em alguns genótipos de Brachiaria ssp., poderia ser responsável pela introdução de 30 a $40 \mathrm{~kg} \mathrm{ha}^{-1}$ de N por ano no sistema soloplanta (Boddey \& Victoria, 1986). Entre as espécies de bactérias diazotróficas associadas a essas plantas, Azospirillum amazonense merece destaque, pois apresenta alta incidência em associação com Brachiaria ssp. (Reis et al., 2001) e adaptabilidade a pH ácido (Baldani et al., 1997), característica comum à maioria dos solos brasileiros.

Como a diversidade de bactérias associativas fixadoras de $\mathrm{N}$ pode, geralmente, estar condicionada à vegetação, é possível que diferentes genótipos de Brachiaria spp. possam exercer efeito seletivo sobre as populações desses microrganismos, o que poderia resultar em diferentes respostas quanto à contribuição da FBN obtida pelas plantas.

O conceito de diversidade, aqui abordado, compreende a diversidade apresentada abaixo do nível de espécie, também chamada de diversidade intra-específica ou microdiversidade (Schloter et al., 2000), pela qual são avaliadas estirpes pertencentes a uma mesma espécie. Para o estudo da diversidade intra-específica, geralmente, são utilizadas técnicas de impressão digital com alta resolução. Isso se deve, em parte, à impossibilidade do uso de métodos tradicionais da microbiologia e à dificuldade de se construir iniciadores e sondas estirpe-específicas, em razão da pequena variabilidade entre as seqüências de nucleotídeos (Ludwig \& Schleifer, 1994). Vários fatores podem influenciar a diversidade intra- 
específica, entre eles, a separação espacial, diferenças ambientais e interações bactéria-hospedeiro (Schloter et al., 2000).

Os ácidos ribonucleicos ribossomais (RNAr) são considerados os biopolímeros mais adequados para estudos de diversidade. Seus genes são universalmente distribuídos e apresentam elevado grau de conservação. Sua variabilidade pode apresentar-se em maior ou menor extensão, em diferentes regiões da molécula (Lane et al., 1985). A técnica conhecida como ARDRA (Análise de restrição de DNA ribossomal amplificado) baseia-se em padrões de restrição enzimática e no grau de conservação dos sítios de restrição do RNAr, que refletem padrões filogenéticos. No entanto, é recomendado cuidado na escolha do fragmento de DNAr a ser amplificado e analisado por esse método.

No caso da análise de diversidade intra-específica, em que existe elevado grau de semelhança genética entre os indivíduos, o fragmento amplificado deve incluir o espaço intergênico 16S-23S DNAr. Esta região apresenta maior variabilidade, tanto em sua composição de bases quanto em seu tamanho, quando comparada com a $16 \mathrm{~S}$ ou 23S DNAr.

Laguerre et al. (1996) caracterizaram 43 estirpes de Rhizobium leguminosarum de diferentes biovares, com a utilização da análise de restrição da região intergênica 16S-23S DNAr. A análise dos padrões de restrição permitiu a diferenciação das estirpes no nível intra-específico. Os autores afirmam que, por meio dos padrões de bandeamento facilmente analisáveis e reproduzíveis, gerados pela restrição da região intergênica, foi possível discriminar as estirpes até o limite determinado pela elevada similaridade existente.

Azevedo (1998) analisou os perfis de restrição da região intergênica 16S-23S DNAr de 71 estirpes de A. amazonense. Seus resultados mostraram, no nível intra-específico, a existência de grande diversidade genética entre essas estirpes.

O objetivo deste trabalho foi de verificar, por meio da análise de restrição do espaço intergênico 16S-23S DNAr, o efeito do genótipo das plantas e sítios de coleta sobre a diversidade intra-específica de isolados de A. amazonense, oriundos de associações com raízes de Brachiaria spp.

\section{Material e Métodos}

As estirpes de A. amazonense, avaliadas neste trabalho, foram isoladas e caracterizadas por Reis Junior et al. (2004) (Tabela 1). As estirpes-padrão de bactérias diazotróficas das espécies $A$. amazonense $\left(\mathrm{Y}^{\mathrm{T}} \mathrm{e}\right.$ CBAMC), A. brasilense $\left(\mathrm{Sp}^{\mathrm{T}}\right.$ e $\left.\mathrm{CD}^{\mathrm{T}}\right)$, A. lipoferum $\left(\mathrm{Sp59} 9^{\mathrm{T}}\right)$ e Herbaspirillum seropedicae $\left(\mathrm{Z} 67^{\mathrm{T}}\right)$, também foram incluídas como controle. Todos os isolados de $A$. amazonense foram obtidos a partir de raízes de B. humidicola, B. decumbens cv. Basilisk ou B. brizantha cv. Marandu, em pastagens do Cerrado (Santo Antônio de Goiás, GO) e em região de Mata Atlântica (Itabela, BA) (Tabela 2).

O método utilizado para extração do DNA dos isolados bacterianos, utilizados como molde para as amplificações específicas via PCR, foi o de lise alcalina das células, adaptado por Audy et al. (1996).

As bactérias foram inoculadas e cresceram, por 48 horas, em meio líquido DYGS ( $\mathrm{g} \mathrm{L}^{-1}$ : glicose 2; peptona 1,5; extrato de levedura $2 ; \mathrm{KH}_{2} \mathrm{PO}_{4} 0,5$; $\mathrm{MgSO}_{4} \cdot 7 \mathrm{H}_{2} \mathrm{O}$ 0,5; ácido glutâmico 1,5). Uma alíquota (1 mL) desta suspensão de células foi centrifugada a $10.000 \mathrm{~g}$ por dois minutos. O sobrenadante foi descartado, e as células ressuspendidas em $1 \mathrm{~mL}$ de água Milli-Q estéril. Esse último procedimento foi repetido três vezes. Depois da última lavagem, repetiu-se a centrifugação e as células foram ressuspendidas em $0,5 \mathrm{~mL}$ de $\mathrm{NaOH}$ $(0,5 \mathrm{~N})$, tendo ficado em repouso por 10 minutos, para a lise completa. Em seguida, $10 \mu \mathrm{L}$ do material lisado foram coletados e diluídos em $490 \mu \mathrm{L}$ de solução de Tris$\mathrm{HCl} 20$ mM, pH 8.

A reação de amplificação da região intergênica 16S-23S DNAr foi realizada em $50 \mu \mathrm{L}$ de uma mistura de reação com $5 \mu \mathrm{L}$ de tampão ( $\mathrm{HCl} 100$ mM;

Tabela 1. Estirpes de Azospirilum amazonense, provenientes de diferentes espécies de Brachiaria, utilizadas neste trabalho $^{(1)}$.

\begin{tabular}{lcc}
\hline B. decumbens & B. humidicola & B. brizantha \\
\hline $37-\mathrm{Ce}$ & $64-\mathrm{Ce}$ & $27-\mathrm{Ce}$ \\
$38-\mathrm{Ce}$ & $77-\mathrm{Ma}$ & $36-\mathrm{Ce}$ \\
$53-\mathrm{Ce}$ & $79-\mathrm{Ma}$ & $48-\mathrm{Ce}$ \\
$72-\mathrm{Ma}$ & $80-\mathrm{Ma}$ & $85-\mathrm{Ma}$ \\
$73-\mathrm{Ma}$ & $81-\mathrm{Ma}$ & $87-\mathrm{Ma}$ \\
$76-\mathrm{Ma}$ & $82-\mathrm{Ma}$ & $104-\mathrm{Ce}$ \\
$116-\mathrm{Ce}$ & $83-\mathrm{Ma}$ & $124-\mathrm{Ce}$ \\
$118-\mathrm{Ce}$ & $84-\mathrm{Ma}$ & $125-\mathrm{Ce}$ \\
$120-\mathrm{Ma}$ & $86-\mathrm{Ma}$ & $131-\mathrm{Ce}$ \\
$134-\mathrm{Ce}$ & $107-\mathrm{Ce}$ & $139-\mathrm{Ma}$ \\
$137-\mathrm{Ce}$ & $119-\mathrm{Ma}$ & \\
$140-\mathrm{Ma}$ & $123-\mathrm{Ce}$ & \\
& $127-\mathrm{Ce}$ & \\
& $132-\mathrm{Ce}$ & \\
& $135-\mathrm{Ce}$ & \\
\end{tabular}

(1)Ce: Cerrados; Ma: Mata Atlântica. 
$\mathrm{KCl} 500 \mathrm{mM}), 6 \mu \mathrm{L}$ de $\operatorname{MgCl}_{2}(25 \mathrm{mM}), 1 \mu \mathrm{L}$ de dNTP (2,5 mM), $1 \mu \mathrm{L}$ (6,67 pmol) dos iniciadores PHR e P23 (Arturo et al., 1995), 0,40 $\mu \mathrm{L}$ de Taq DNA Polimerase (5 $\mathrm{U}^{-1} \mathrm{~L}^{-1}$ ) (Promega, Madison, EUA) e $2 \mu \mathrm{L}$ (100 ng) de amostra de DNA molde. As reações de amplificação consistiram de uma etapa inicial de desnaturação $\left(95^{\circ} \mathrm{C}\right.$ por 3 minutos), seguida por 35 ciclos intermediários $\left(94^{\circ} \mathrm{C}\right.$ por 1 minuto; $60^{\circ} \mathrm{C}$ por 1 minuto; $72^{\circ} \mathrm{C}$ por 3 minutos), e uma etapa terminal de extensão $\left(72^{\circ} \mathrm{C}\right.$ por 5 minutos) e resfriamento $\left(15^{\circ} \mathrm{C}\right.$ por 15 minutos).

Os fragmentos amplificados foram separados por eletroforese, em gel de agarose 1,2\%, em tampão TAE, a $65 \mathrm{~V}$, por 2,5 horas. As bandas resolvidas no gel foram visualizadas após coloração com brometo de etídeo, sob iluminação ultravioleta, e fotografadas com filme Polaroid tipo 667.

Os produtos de amplificação das reações de PCR foram incubados a $37^{\circ} \mathrm{C}$ em banho-maria, por 3 horas, com as endonucleases de restrição HaeIII, AluI, RsaI e CfoI (GibcoBRL, Gaithersburg, EUA). Para um volume final de $15 \mu \mathrm{L}$ de reação, cada sistema de restrição conteve $5 \mathrm{U}$ da enzima de interesse, 1,5 $\mu \mathrm{L}$ de tampão de reação (HCl 100 mM; KCl 500 mM) e $8 \mu \mathrm{L}$ de material amplificado. Os produtos da reação foram submetidos à eletroforese em gel de agarose $(3 \%$ em tampão TAE), a $50 \mathrm{~V}$ por quatro horas. Posteriormente, os géis foram visualizados depois da coloração com brometo de etídeo, sob iluminação ultravioleta, e fotografados com filme Polaroid tipo 667.

Depois da restrição, foi construída uma matriz binária, com os dados obtidos da análise do universo total das bandas, de todos os perfis gerados pelas quatro enzimas. Para cada posição de migração foram atribuídos os valores de 1 ou 0 , indicando a presença ou ausência de uma banda. Os padrões de migração gerados foram comparados, e suas semelhanças estimadas pelo coeficiente de Jaccard (Rohlf, 1994) $\mathrm{J}=\mathrm{a} /(\mathrm{n}-\mathrm{d}$ ), em que a é o número de combinações com a presença dos fragmentos, menos as combinações de ausência dos fragmentos, d é o número de combinações de ausência de fragmentos e n é o número de combinações possí- veis. Os isolados foram agrupados pelo método das médias das distâncias e representados, graficamente, por um dendrograma (NTSYS-pc, versão 2.1, Exeter Software, USA).

Os dados derivados da matriz foram incorporados em um formato de análise de variância, utilizando-se a AMOVA (Analysis of Molecular Variance), que produz estimativas dos componentes da variância, assim como um teste análogo ao teste F (Excoffier et al., 1992).

\section{Resultados e Discussão}

Os produtos de amplificação da região intergênica 16S-23S DNAr (38 isolados) variaram de acordo com as espécies analisadas. A amplificação desta região, para a espécie A. amazonense, originou três fragmentos característicos (Azevedo, 1998) de aproximadamente 1.000 a $1.300 \mathrm{pb}$ (Figura 1). Dois destes fragmentos, de aproximadamente $1.000 \mathrm{pb}$, foram intensamente amplificados e observados, quando separados por eletroforese em gel de agarose. A. brasilense e A. lipoferum apresentaram padrão idêntico entre si, com a presença de dois fragmentos entre 1.000 e 800 pb. Um único fragmento, de aproximadamente $1.000 \mathrm{pb}$, foi observado quando a espécie analisada foi $H$. seropedicae.

Estes resultados estão de acordo com a literatura. Na verdade, em contraste aos genes do RNAr, que são bastante conservados entre a maioria das espécies de procariotos, para a região intergênica é esperado que existam múltiplas cópias e que essas geralmente se diferenciem quanto ao tamanho e composição (Dolzani et al., 1995), podendo ainda carregar seqüências conservadas com papéis funcionais (genes de RNAt, seqüências antiterminação) (Sievers et al., 1996).

Quando os produtos de amplificação apresentam apenas um fragmento, existe a possibilidade de que no genoma deste microrganismo haja apenas uma seqüência alvo ou que, pelo menos, o tamanho das múltiplas cópias seja semelhante (Dolzani et al., 1995). Um exemplo da variabilidade do tamanho e do número de cópias, nessa região, é dado por Lagatolla et al. (1996), que ao

Tabela 2. Características edafoclimáticas dos locais de coleta de raízes de Brachiaria, em Goiás e na Bahia(1).

\begin{tabular}{|c|c|c|c|c|c|c|c|c|c|}
\hline Local de coleta & Classificação do solo & $\mathrm{pH}\left(\mathrm{H}_{2} \mathrm{O}\right)$ & $\begin{array}{c}\mathrm{Al}^{3+} \\
----(\mathrm{c}\end{array}$ & $\begin{array}{c}\mathrm{Ca}^{2+} \\
\mathrm{mol}_{\mathrm{c}} \mathrm{dn}\end{array}$ & $\begin{array}{l}\mathrm{Mg}^{2+} \\
\left.\mathrm{a}^{-3}\right)----\end{array}$ & $\begin{array}{c}\mathrm{K}^{+} \\
---(\mathrm{mg} \mathrm{k}\end{array}$ & $\begin{array}{c}P \\
\left.g^{-1}\right)-- \\
\end{array}$ & Textura & Clima (Köppen) \\
\hline Goiás $\left(16^{\circ} 28^{\prime} \mathrm{S}\right.$ e $\left.49^{\circ} 17^{\prime} \mathrm{W}\right)$ & Latossolo Vermelho-Escuro & 5,3 & 0,1 & 3,0 & 1,7 & 104,0 & 2,0 & Franco-argilosa & Aw (tropical com estação seca no inverno) \\
\hline Bahia $\left(16^{\circ} 39^{\prime} \mathrm{S}\right.$ e $\left.39^{\circ} 30^{\prime} \mathrm{W}\right)$ & Argissolo Amarelo & 5,8 & 0,2 & 2,6 & 1,5 & 78,0 & 2,0 & Areia-franca & Af (tropical sem estação seca) \\
\hline
\end{tabular}


caracterizar diferentes serotipos de Salmonella, mostraram quatro a oito fragmentos, com variação de 700 a $1.100 \mathrm{pb}$, como produtos de amplificação do espaço intergênico 16S-23S. Esses autores concluíram que diferentes serotipos de Salmonella são caracterizados por diferentes padrões do espaço intergênico. A presença de apenas um fragmento, depois da amplificação do espaço intergênico, foi demonstrada nos estudos de identificação de aceto-bactérias (Ruiz et al., 2000), que indicaram que não existem variações quanto ao tamanho desta região, entre estirpes desse grupo.

O dendrograma construído a partir dos perfis de restrição (Figura 2) apresentou diversidade entre os isolados, com a formação de dois grupos principais, definidos em nível de apenas 56\% de similaridade. Azevedo (1998), em estudo semelhante, com isolados de A. amazonense, provenientes de arroz, milho e sorgo, cultivados em dois diferentes tipos de solo, revelou a existência de cinco grupos distintos, formados a $78 \%$ de similaridade. Esse comportamento evidencia, no nível intra-específico, a presença de diversidade genética entre os isolados. De maneira similar, Rosado et al.
(1998) também observaram grande heterogeneidade genética entre isolados de Paenibacillus azotofixans, oriundos da rizosfera e rizoplano de diversas gramíneas. É possível que os padrões genotípicos diversos, dos isolados de A. amazonense, possam ser reflexo da elevada capacidade de sobrevivência e colonização dessa espécie. Além disso, as alterações no genoma bacteriano, a recombinação e os processos naturais seletivos e evolutivos também poderiam ser responsáveis pela grande diversidade observada (Azevedo, 1998).

Os resultados não apresentaram, de maneira clara, uma possível influência dos sítios experimentais sobre a diversidade dos isolados analisados (Figura 2 e Figura 3A), apesar de serem comuns os relatos que evidenciam influência do tipo de solo sobre a diversidade gênica de isolados, geralmente atribuída às diferentes características ambientais (químicas, físicas e biológicas). Latour et al. (1996) demonstraram intensa influência, exercida pelo tipo de solo, sobre a estrutura populacional de isolados de Pseudomonas, e sugeriram que as diferentes características ambientais existentes poderiam ser as responsáveis pelo efeito discriminatório apresentado.

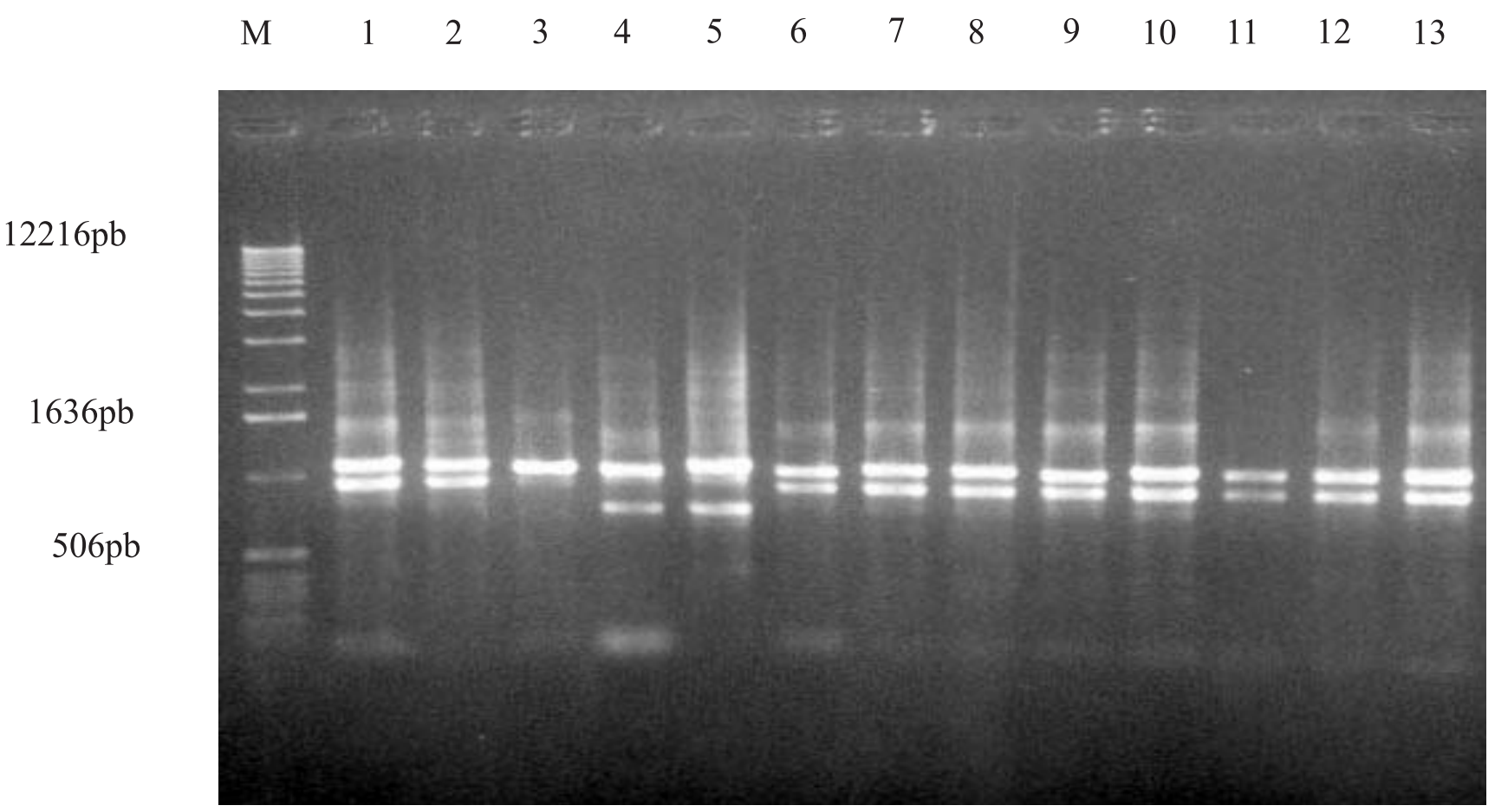

Figura 1. Produtos de amplificação da região intergênica 16S-23S DNAr, de estirpes-referência de diferentes diazotróficos e novos isolados de Azospirillum amazonense provenientes de três espécies de Brachiaria spp. M (marcador 1Kb Ladder); 1(Y2); 2 (CBAMC); 3 (Z67); 4 (Sp7); 5 (Sp59); 6 (118); 7 (27); 8 (84); 9 (135); 10 (85); 11 (37); 12 (38);13 (73). 
Dalmastri et al. (1999) compararam o efeito de diferentes tipos de solo, cultivares de milho e localização radicular sobre a microdiversidade de Burkholderia cepacia. Seus resultados indicaram que, entre todos os fatores estudados, o solo foi o que apresentou maior efeito sobre a diversidade dos isolados. Azevedo (1998) também mostrou uma indiscutível influência do solo (Podzólico Vermelho-Amarelo ou Hidromórfico Cinzento) sobre a diversidade de A. amazonense.

Neste trabalho, a influência das espécies de Brachiaria spp. sobre a diversidade dos isolados analisados pode ser notada mais claramente. De acordo com a AMOVA, a $10 \%$ de significância, houve separação entre grupos, dependendo da espécie de Brachiaria de onde as estirpes foram isoladas. Analisando-se a Figura 2 e a Figura 3 B, observa-se que a maioria dos isolados de $B$. decumbens e $B$. brizantha estão presentes no grupo I, e que os isolados de B. humidicola concentram-se no grupo II.
Um fato interessante é que $B$. decumbens cv. Basilisk (cultivar utilizada neste trabalho) é, na verdade, um ecótipo intermediário entre as espécies de B. brizantha e B. decumbens (Valle et al., 2000). Enquanto B. decumbens cv. Basilisk e B. brizantha cv. Marandu são tetraplóides, $B$. humidicola é hexaplóide. Segundo Valle et al. (2000), este tipo de análise permite inferir sobre a distância genética entre os acessos de Brachiaria.

A composição de plantas, em uma determinada área, pode influenciar a diversidade da comunidade microbiana, em conseqüência da variabilidade da composição química de seus exsudatos. Estes compostos influenciam a comunidade microbiana e alteram a composição química do solo nas vizinhanças das raízes, servindo como substratos seletivos para o crescimento dos microrganismos do solo. Na verdade, a variedade de compostos orgânicos liberados pelas plantas tem sido enfatizada como o fator chave de influência na diversidade de mi-

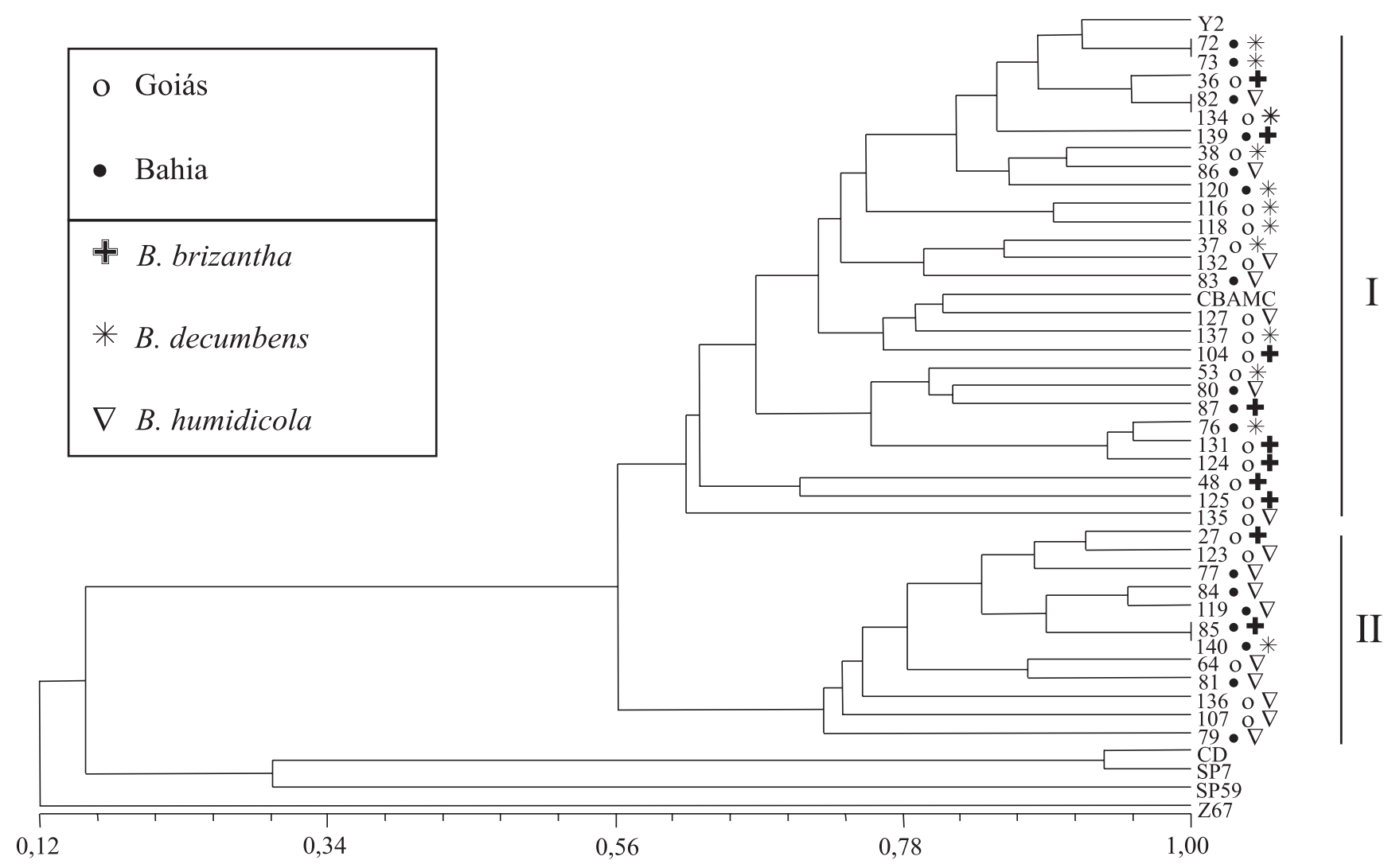

Figura 2. Dendrograma de similaridade de 38 isolados de raízes de Brachiaria spp. (evidenciando os locais de coleta e as espécies de origem) e das estirpes-referência de Azospirillum amazonense (CBAMC, Y2), A. brasilense (CD, Sp7), A. lipoferum (Sp59) e Herbaspirillum seropedicae (Z67). Este dendrograma foi gerado pelo algoritimo UPGMA e matriz de similaridade Jaccard, a partir dos dados da região intergênica 16S-23S DNAr, amplificada por PCR e submetida à restrição com as enzimas HaeIII, AluI, RsaI e CfoI. 
crorganismos presentes na rizosfera de diferentes espécies vegetais (Bowen \& Rovira, 1991 citados por Grayston et al., 1998).

Sabe-se que a quantidade e qualidade dos exsudatos e compostos relacionados, liberados no solo pelas raízes das plantas, pode variar em função de vários fatores além da espécie da planta, como região da raiz, tipo de solo, condição nutricional, idade e estresses, dentre outros (Yang \& Crowley, 2000).

Latour et al. (1996) observaram efeitos discriminatórios de plantas sobre isolados de Pseudomonas, quando cultivadas em um mesmo solo. Zhang et al. (1999), citados por Schloter et al. (2000), investigaram a filogenia e diversidade de 22 estirpes de $B$. japonicum, isoladas de nódulos de duas cultivares de amendoim. Utilizando marcadores fenotípicos e genotípicos, estes autores demonstraram uma forte influência das cultivares sobre a diversidade desses microrganismos.

Azevedo (1998) mostrou que a microdiversidade de A. amazonense, em isolados do interior de raízes, poderia estar sendo influenciada pela espécie da planta, com efeitos discriminatórios exercidos por plantas de arroz, milho e, em menor intensidade, sorgo. Em razão dessas evidências, esse autor propôs que os padrões de especificidade da interação A. amazonense-planta pudessem ocorrer não em nível de espécie, mas sim de estirpes.

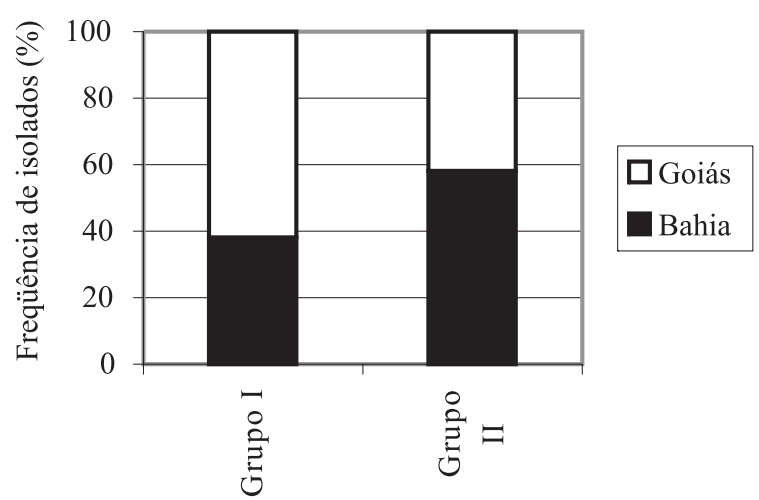

Grupos de similaridade
Os resultados deste trabalho, que mostram a presença de estirpes de bactérias diazotróficas geneticamente diferentes, associadas a diferentes espécies de Brachiaria, podem ser indicados como um dos possíveis fatores de influência nas taxas de FBN associadas a essas plantas, assim como na sua adaptabilidade a solos de baixa fertilidade. Os estudos para a quantificação da FBN efetuados por Boddey \& Victoria (1986), em que foi utilizada a metodologia de diluição isotópica de ${ }^{15} \mathrm{~N}$, demonstraram que as espécies $B$. decumbens e $B$. humidicola receberam uma quantidade de $\mathrm{N}$, via FBN, bem mais significativa que aquelas apresentadas por B. radicans e B. ruziziensis. Loureiro (1985) ao utilizar esta mesma metodologia, demonstrou que as raízes de $B$. humidicola apresentaram um enriquecimento de ${ }^{15} \mathrm{~N}\left(\%{ }^{15} \mathrm{~N}\right)$ significativamente menor que as outras espécies estudadas, o que sugere uma maior contribuição da FBN para esta espécie.

A associação entre Azospirillum sp. e Brachiaria sp. nos faz vislumbrar a possibilidade de inoculação dessa bactéria em áreas de pastagens. Itzigsohn et al. (2000) mostraram que a inoculação de Azospirillum sp. em pastagens tem grande potencial para tornar-se uma técnica aplicável a sistemas em condições de deficit hídrico e baixa fertilidade. Apesar de existirem formulações de inoculantes de Azospirillum comercialmente disponíveis em alguns países, estudos sobre sua utilização ou de outras rizobactérias promotoras do crescimento de plan-

(B)

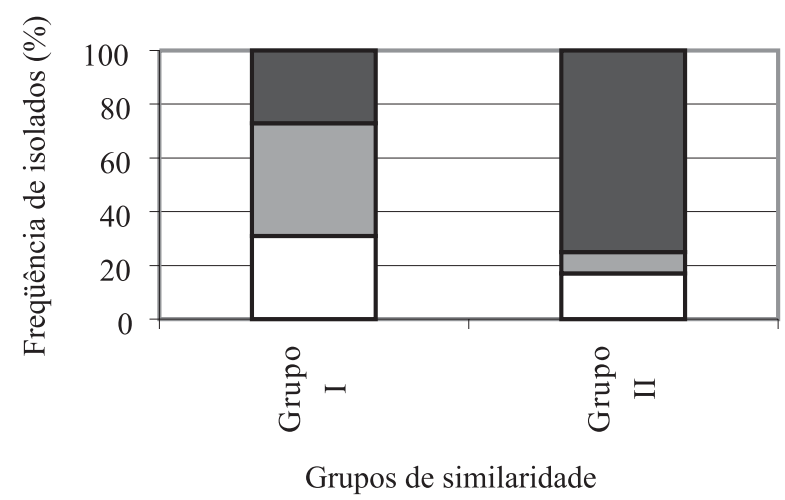

$\square$ B. brizantha $\square$ B. decumbens $\square$ B.humidicola

Figura 3. Freqüência dos isolados de A. amazonense, contidos em cada grupo de similaridade, formados pela restrição da região intergênica 16S-23S DNAr amplificada, apresentados na Figura 2, levando-se em consideração o local de coleta das amostras (A) e a espécie de Brachiaria associada a esses isolados (B). As freqüências foram obtidas pela divisão do número de isolados de cada sítio (A) ou espécie (B), representados em determinado grupo, pelo número total de isolados presentes nesse grupo. 
tas, em pastagens, são muito escassos. Ainda não existem informações suficientes sobre os efeitos da inoculação de Azospirillum sp. nessas áreas. No entanto, o uso destes microrganismos, associado a um adequado manejo do solo, em comparação com a aplicação de fertilizantes, parece ser vantajoso economicamente e, do ponto de vista ecológico e ambiental, não apresenta relativamente nenhum impacto ao meio-ambiente (Itzigsohn et al., 2000).

\section{Conclusão}

As espécies de Brachiaria podem influenciar a diversidade de estirpes de $A$. amazonense a elas associadas.

\section{Referências}

ARTURO, A.; ODELSOR, D.A.; HICHEY, R.F.; TIEDJE, J.M. Bacterial community fingerprint of amplified 16S and 16S-23S ribosomal DNA gene sequences and restriction endonuclease analysis (ARDRA). In: AKKERMANS, A.D.L.; ELSAS, J.D. van; BRUIJN, F.J. de (Ed.). Molecular microbial ecology manual. Dordrecht: Kluwer Academic Publishers, 1995. p.1-8.

AUDY, P.; BRAAT, C.E.; SAINDON, G.; HUANG, H.C.; LAROCHE, A. A rapid and sensitive PCR-based assay for concurrent detection of bacteria causing common and halo blights in bean seed. Phytopathology, v.86, p.361-366, 1996.

AZEVEDO, M.S. Influência do solo e da planta hospedeira sobre a diversidade gênica de isolados de Azospirillum amazonense associados às raízes de arroz, milho e sorgo. 1998. 110p. Dissertação (Mestrado) - Universidade Federal Rural do Rio de Janeiro, Seropédica.

BALDANI, J.I.; CARUSO, L.; BALDANI, V.L.D.; GOI, S.R.; DÖBEREINER, J. Recent advances in BNF with non-legume plants. Soil Biology and Biochemistry, v.29, p.911-922, 1997.

BODDEY, R.M.; VICTORIA, R.L. Estimation of biological nitrogen fixation associated with Brachiaria and Paspalum grasses using ${ }^{15} \mathrm{~N}$ labelled organic matter and fertilizer. Plant and Soil, v.90, p.265292, 1986

DALMASTRI, C.; CHIARINI, L.; CANTALE, C.; BEVIVINO, A.; TABACCHIONI, S. Soil type and maize cultivar affect the genetic diversity of maize root-associated Burkholderia cepacia populations. Microbial Ecology, v.38, p.273-284, 1999.

DOLZANI, L.; TONIN, E.; LAGATOLLA, C.; PRANDIN, L.; MONTI-BRAGADIN, C. Identification of Acinetobacter isolates in the A. calcoaceticus - A. baumannii complex by restriction analysis of the 16S-23S rRNA intergenic spacer sequences. Journal of Clinical Microbiology, v.33, p.1108-1113, 1995.

EXCOFFIER, L.; SMOUSE, P.E.; QUATTRO, J.M. Analysis of molecular variance inferred from metric distances among DNA haplotypes application to human mitochondrial DNA restriction data. Genetics, v.131, p.479-491, 1992.

GRAYSTON, S.J.; WANG, S.; CAMPBELL, C.D.; EDWARDS, A.C. Selective influence of plant species on microbial diversity in the rizosphere. Soil Biology and Biochemistry, v.30, p.369-378, 1998.

ITZIGSOHN, R.; BURDMAN, S.; OKON, Y.; ZAADY, E.; YONATAN, R.; PEREVOLOTSKY, A. Plant-growth promotion in natural pastures by inoculation with Azospirillum brasilense under suboptimal growth conditions. Arid Soil Research and Rehabilitation, v.14, p.151-158, 2000.

LAGATOLLA, C.; DOLZANI, L.; TONIN, E.; LAVENIA, A.; DI MICHELE, M.; TOMMASINI, T.; MONTI-BRAGADIN, C. PCR ribotyping for characterizing Salmonella isolates of different serotypes. Journal of Clinical Microbiology, v.34, p.2440-2443, 1996.

LAGUERRE, G.; MAVINGUI, P.; ALLARD, M.R.; CHARNAY, M.P.; LOUVRIER, P.; MAZURIER, S.I.; RIGOTTIER-GOIS, L.; AMARGER, N. Typing of rhizobia by PCR DNA fingerprinting and PCR - restriction fragment length polymorphism analysis of chromosomal and symbiotic gene regions: application to Rhizobium leguminosarum and its different biovars. Applied and Environmental Microbiology, v.62, p.2029-2036, 1996.

LANE, D.L.; PACE, B.; OLSEN, G.J.; STAHL, D.A.; SOGIN, M.L.; PACE, N.R. Rapid determination of $16 \mathrm{~S}$ ribossomal RNA sequences for phylogenetic analyses. Proceedings of National Academy of Science, v.82, p.6955-6959, 1985.

LATOUR, X.; CORBERAND, T.; LAGUERRE, G.; ALLARD, F.; LEMANCEAU, P. The composition of fluorescent pseudomonad populations associated with roots is influenced by plant and soil type. Applied and Environmental Microbiology, v.62, p.24492456, 1996.

LOUREIRO, M.F. Balanço de nitrogênio em gramíneas do gênero Brachiaria. 1985. Dissertação (Mestrado) - Universidade Federal Rural do Rio de Janeiro, Seropédica.

LUDWIG, W.; SCHLEIFER, K.H. Bacterial phylogeny based on 16S and 23S rRNA sequence analysis. FEMS Microbiology Reviews, v.15, p.155-173, 1994.

REIS, V.M.; REIS JUNIOR, F.B. dos; QUESADA, D.M.; OLIVEIRA, O.C.A. de; ALVES, B.J.R.; URQUIAGA, S.; BODDEY, R.M. Biological nitrogen fixation associated with tropical pasture grasses. Australian Journal of Plant Physiology, v.28, p.837844, 2001.

REIS JUNIOR, F.B.; SILVA, M.F.; TEIXEIRA, K.R.S.; URQUIAGA, S.; REIS, V.M. Identificação de isolados de Azospirillum amazonense associados a Brachiaria spp., em diferentes 
épocas e condições de cultivo e produção de fitormônio pela bactéria. Revista Brasileira de Ciência do Solo, v.28, p.103-113, 2004.

ROHLF, F.J. NTSYS-pc: numerical taxonomy and multivariate analysis system: version 2.1 user guide. New York: Exeter Software, 1994. 39p.

ROSADO, A.S.; DE AZEVEDO, F.S.; DA CRUZ, D.W.; VAN ELSAS, J.D.; SELDIN, L. Phenotypic and genetic diversity of Paenibacillus azotofixans strains from the rhizoplane or rhizosphere soil of different grasses. Journal of Applied Microbiology, v.84, p.216-226, 1998.

RUIZ, A.; POBLET, M.; MAS, A.; GUILlAMÓN, J.M. Identification of acetic acid bacteria by RFLP of PCR-amplified 16S rDNA and 16S-23S rDNA intergenic spacer. International Journal of Systematic and Evolutionary Microbiology, v.50, p.1981-1987, 2000.
SCHLOTER, M.; LEBUHN, M.; HEULIN, T.; HARTMANN, A. Ecology and evolution of bacterial microdiversity. FEMS Microbiology Reviews, v.24, p.647-660, 2000.

SIEVERS, M.; ALONSO, L.; GIANOTTI, S.; BOESCH, C.; TEUBER, M. 16S-23S ribossomal RNA spacer regions of Acetobacter europaeus and A. xylinum, tRNA genes and antitermination sequences. FEMS Microbiology Letters, v.142, p.43-48, 1996.

VALLE, C.B.; EUCLIDES, V.P.B.; MACEDO, M.C.M. Características das plantas forrageiras do gênero Brachiaria. In: SIMPÓSIO SOBRE MANEJO DA PASTAGEM, 17., 2000, Piracicaba. A planta forrageira no sistema de produção: anais. Piracicaba: Fealq, 2000. p.65-108.

YANG, C.H.; CROWLEY, D.E. Rhizosphere microbial community structure in relation to root location and plant iron nutritional status. Applied and Environmental Microbiology, v.66, p.345-351, 2000.

Recebido em 10 de fevereiro de 2005 e aprovado em 5 de agosto de 2005 